\title{
Analysis of Frames with and Without Knee Bracing for Lateral Loads Using Steel Structures
}

\author{
K. Kanishkavya ${ }^{1 *}$, D. Sivakumar ${ }^{2}$ M. Velumani ${ }^{2}$ \\ ${ }^{1}$ PG Student, Department of Civil Engineering, K.S.Rangasamy College of Technology, Tiruchengode, Tamil Nadu, \\ India. \\ ${ }^{2}$ Professor, Department of Civil Engineering, K.S.Rangasamy College of Technology, Tiruchengode, Tamil Nadu, \\ India.
}

*Corresponding author E-Mail ID: kanishkavyakannan@gmail.com

Doi: https://doi.org/10.34256/irjmtcon69

\begin{abstract}
Steel has become the predominate material for the construction of bridges, buildings, towers and other structures. Its great strength, uniformity light weight and many other desirable properties makes steel the material of choice for numerous structures such as steel bridges, high rise buildings, towers and other structures. The advantages in general credited to steel as a structural design material are high strength/weight ratio, ductility, predictable material properties, speed of erection structures, and quality of construction ease of repair, adaptation of prefabrication, repetitive use, expanding existing structures and fatigue strength. Steel structures should be stiff enough to limit the drift and should have enough ductility to prevent collapse. In this steel bracing provides an effective and economical solution for resisting lateral loads in a framed structure. Knee braced steel frame is that of excellent ductility and lateral stiffness. Since the knee element is properly fused, yielding occurs only to the knee element and no damage to major elements In this study, the effect of different types of bracing in comparison with knee braced steel frame are studied and analysed using software.
\end{abstract}

Keywords: Knee braced steel frame, ductility, predictable material properties.

\section{INTRODUCTION}

Among the different natural hazards, earthquake is one of the most devastating threats which has a severe effect on the safety and welfare of human beings. Building which appear to be strong enough found to be crumbling during strong ground motions. The reasons why the existing structures are under threat are ignorance of building code provisions, wrong construction practices and lack of knowledge of earthquake resistant design. The demolition of existing structures and reconstruction as per the code description is impractical, uneconomical and time consuming so that, the major disasters are avoided. For this, the deficient buildings should be identified first and detailed evaluation is to be carried out to check their strength and performances. Structures which are subjected to lateral load must have adequate stiffness and strength which helps to controlling the deflection and also prevents any damage which may occur.

Braces are used to resist lateral forces in a steel structure while the structures are under seismic excitation. In the case of knee elements, since the damage is concentrated in a secondary member, it can be easily repaired or replaced at minimum cost. So in this study, different knee elements are used in structures and analyzing their resistance against seismic forces. Knee Braced 
Frames are the frames in which a non buckling diagonal member provides most of the lateral stiffness. The flexural or shear yielding of the knee element provides the ductility under a severe earthquake. In this way, the damage is concentrated in a secondary member, which can be easily repaired or replaced at minimum cost. Moreover large seismic impact can be greatly resisted by encouraging the ordinary braced frames with various bracing configurations

The planet greatest hazards are earthquake, which will vary along the magnitude on the Richter scale. The demolition of existing structures and reconstruction as per the code description is impractical, uneconomical and time consuming so that, the major disasters are avoided. For this, the deficient buildings should be identified first and detailed evaluation is to be carried out to check their strength and performances. The earthquake load which is acting on the base foundation called base shear. And the load which was acting on slab of each and every storey high is known as lateral load. Knee bracings are used to resist lateral load in steel structures. Which will be used for steel structure as retrofitting?

In case of knee elements, since the damage is concentrated in a secondary member, it can be easily repaired or replaced at minimum cost. So, in this study, different knee elements are used in structures and analyzing their resistance against seismic forces. As far as Knee braced frames are concerned that can be utilized as nonlinear bulking diagonal member, that can provide the maximum lateral stiffness. The yielding shear or flexural member that can provide ductility under heavier seismic effects. However, the higher seismic impact can be greatly minimizing the length of various bracing configurations.

As it is even less cost in case retrofitting the knee elements. Choudhari V.A, Dr. T. K. Nagaraj, et. al (2015). From this journal want I had extract was the major concept of seismic resisting building frames of $\mathrm{X}$ braced, Chevron, inverted V, and Knee braced frames in steel structures. Here the SAP2000 software has been used which would help me to identify the ETABS for my project. The G+4 steel bare frame was considered and compared in different bases.

As the plotted results were taken from the following computer software. The pushover analysis has done in order to identify the base shear and performance point. Ratnesh Kumar, Prof. K. C. Biswal, et.al (2014). The study of braced steel frame response is widely studied in many branches of Structural engineering. Many researchers have been deeply studying these structures, over the years, mainly for their greater capacity of carrying external loads. Model 1 is a Steel Moment Resisting Frame (SMRFs) with concentric bracing as per IS 800-2007. Cross bracing, diagonal bracing and an unbraced frame is considered for study.

Model 2 consist of two Steel Moment Resisting Frame with similar V type bracing and Inverted V (Chevron bracing) configuration, but with varying height. Performance of each frame is studied through Equivalent static analysis, Response Spectrum analysis, and linear Time History analysis. Anitha M, Divya K.K. et. al (2015) The knee bracing frames could be in farther classified by Finite element method. In order to determine the exact determination in approximate methodology.

In this journal the 2D frame has been taken into consideration and as we generally consider it in a piece of paper to write down it considers as single frame structure to calculation external force. A single diagonal frame is considered and the double knee bracing has taken. Due to strength to weight ratio the properties of material, ductility, quality of structure is adopted. The main aim is to compare Knee braced frame with eccentricity. Which Nonlinear static analysis and nonlinear time history analysis is determined by using computer software Ansys in order to identify the means of EI Centro earthquake data from recorded data. By this the ultimate load and stiffness were calculated. Arathi Thamarakshan, Prof. Arunima. S et. al (2017) Steel braced frame is one of the structural systems used to resist earthquake loads in structures. Steel bracing is 
economical, easy to erect, occupies less space and has flexibility to design for meeting the required strength and stiffness. Bracing can be used as retrofit as well.

There are various types of steel bracings are available. In the present study, steel frame with various configurations are analyzed by ETABS software. The results of time history analysis were then compared with the results of the pushover analysis. The study also involving the analysis for suggesting the best configurations. Mahnoud Miri, Abdolreza Zare, Hossein Abbas Zadeh. et. al (2009).

Frames with similar dimensions but various heights in both systems are designed according to Iranian code of practice for seismic resistant design of building, and then based on a nonlinear push over static analysis; the seismic parameters such as behavior factor and performance levels are compared. By studying tables related to seismic parameters it is proved that whatever the stages increased the over strength factor reduced and also the ductility factor are increased.

The amount of dissipating and energy absorption in chevron knee braces system is more than ordinary knee braces system which indicates high ductility of chevron knee braces system against stiffness of ordinary knee braces system. Jinkoo Kim, Junhee Park, Prof. Sang-Dae Kim. et. al (2009). The seismic behaviour of a framed structure with chevron-type buckling restrained braces was investigated and their behaviour factors, such as overstrength, ductility, and response modification factors, were evaluated. Two types of structures, building frame systems and dual systems, with 4, 8, 12, and 16 stories were designed per the IBC 2003, the AISC LRFD and the AISC Seismic Provisions. Nonlinear static pushover analyses using two different loading patterns and incremental dynamic analysis using 20 earthquake records were carried out to compute behavior factors. Time history analyses were also conducted with another 20 earthquakes to obtain dynamic responses. The dual systems, even though designed with smaller seismic load, showed superior static and dynamic performances.

Leelataviwat.S, Doung.P, Prof. Junda. E, Chan-anan.W. et. al (2017). This paper presents the behavior and design concept of efficient structural steel systems based on innovative applications of knee braces. Advantages of knee-braced frames (KBF) include relatively simple connections for ease of construction and reparability after an earthquake and less obstruction as compared to conventional bracing systems. Various configurations of KBFs can be designed and detailed for different levels of strength, stiffness, and ductility. KBFs are designed so that all inelastic activities are confined to the knee braces and designated yielding elements only.

Key design concepts to ensure ductile behaviour of KBFs are first summarized. Finally, results from experimental and analytical studies into the behaviour of KBFs are briefly presented. The results show that KBFs can provide viable alternatives to conventional structural systems. The seismic behavior on G+ 5 structural models with different bracing arrangements for investigation. The internal storey drift in X-direction is far compared to permissible drift ratio as per IS 1893:2002 (part 1). Hence the knee braced frame system is significant to reduce the effect on lateral displacement by spectral acceleration $(\mathrm{Sa})$. The internal storey drift in Y-direction is far compared to permissible drift ratio as per IS 1893:2002 (part-1). Therefore, the knee bracing frame structural internal storey drift is acceptable by IS 1893:2002 (part 1).

Steel plays an important role in construction industry due to its high strength to weight ratio. A study regarding the seismic response of steel structures is necessary. The present study is intending to perform pushover analysis for different knee braced frames and then to compare their responses with the time history analysis using ETABS. Further, suggesting the best configuration that can be used to resist seismic forces.

From the nonlinear studies that were conducted on different configurations of knee braced frames, the following conclusions can be made; The behaviour of building is studied for different 
parameters like storey shear, storey displacement, etc. by pushover analysis and time history analysis. Among the three cases, cross braced configuration was found to be effective under seismic loading. Here, braces are arranged in $\mathrm{X}$ shape so that it will contributes structural stiffness and reduces the maximum interstate drift of steel buildings. Diagonal braced frame having the least resistance to seismic forces because it having only one diagonal element which reduces the lateral stiffness during earthquake. So cross braced configuration is most suitable as compared to others that can be adopted for seismic resistance.

\section{REFERENCES}

1. Abou.E.HandGhobaraha.A,'Rehabilitation of a Reinforced Concrete Frame using Eccentric steel bracing",Engineering Structures, Vol23(2001),pp.745-755.

2. Adedeji, A.A,'Comparative Study Of Seismic Analysis For Reinforced Concrete Frame Infill With Masonry and Shape Memory Alloy Wires",Trends in Applied Sciences Research,Vol 6,(2011),pp.426- 437.

3. Akbari.R,Maheri.HandMahmoud.R,'Seismic Behaviour Factor,R, for Steel X-braced and kneebraced RC buildings",EngineeringStructures, Vol 25,(2003),pp.1505-1513.

4. Chih.Y.L andThambirajah.B,'EarthquakeResistant Steel Frames with energy dissipating knee elements",EngineeringStructures,Vol 17(1995),pp.334-343.

5. Chuang.S.Y, Reginald.D.R, and Roberto.T.L,'Pushover Response of a Braced Frame with Suspended Zipper Struts",Journal of Structural Engineering,Vol 134(2008),pp.1619-1626.

6. IS: 1893-2002 (part-1) “CRITERIA FOR EARTHQUAKE RESISTANT DESIGN OF STRUCTURES"fifth revision, Bureau of Indian Standards, New Delhi.

7. N.Joseph, Jebin.J, andTinto.G,'Seismic Performance Evaluation of Steel Frames with Knee braces Based on Pushover Analysis",International journal of advanced engineering sciences and technologies, Vol 4(2016),pp.242-267. Anitha M, Divya K.K, "Comparative Study On Seismic Behavior Of Steel Knee Braced Frame With Eccentric Braced Frame”. IOSR Journal of Mechanical and Civil Engineering e-ISSN: 2278-1684,p-ISSN: 2320-334X, PP 01-07.

8. D. Kawai, Osaka Institute of Technology, Osaka, Japan, K. Suita Kyoto University, Y. Koetaka \&, Tokyo, Japan, K. Inoue General Building Research Corporation of Japan (RCJ), Osaka, Japan, N. Uno \& Y. Fukuchi Nippon Steel \& Sumaiken Metal Products Corporation, Ltd., Tokyo, Japan. "Mechanical behavior and design method of weld-free steel structure with knee brace damper using square tube column". 2012.

9. Leelataviwat, S. \& Doung, P. CE Department, King Mongkut's University of Technology Thonburi, Thailand. "Ductile Knee-Braced Frames for Seismic Applications". International Conference on Earthquake engineering and Structural Dynamics. June-2017.

10. Viswanath.K.G, Prakash K.B, Anant Desai, Director/Principal, Ashokrao Mane Group of Institutions, Vathar Tarf Vadgaon, Kolhapur.Seismic Analysis of Steel Braced Reinforced Concrete Frames".

11. HUANG Zhen, LI Qing-song, CHEN Long-zhu, (2005), "Elastoplastic analysis of knee bracing frame," Journal of Zhejiang University Science.

12. MehrdadLotfollahi, MassoodMofid (2006), "On the design of new ductile knee bracing, Journal of Constructional Steel Research 62, pp 282-294

13. Mahmoud Miri, Abdolreza Zare, Hossein Abbas zadeh,(2009), "Seismic behavior of steel frames investigation with knee brace based on pushover analysis," World Academy of Science, Engineering and Technology. 